\title{
Pre-smoke-ban café staff job satisfaction and attitudes in transition countries
}

\author{
Ljudevit Pranić $^{1 *}$, Snježana Pivac ${ }^{2}$ and Anela Čolak ${ }^{3}$
}

Received: 14/09/2012 Accepted: 18/12/2012

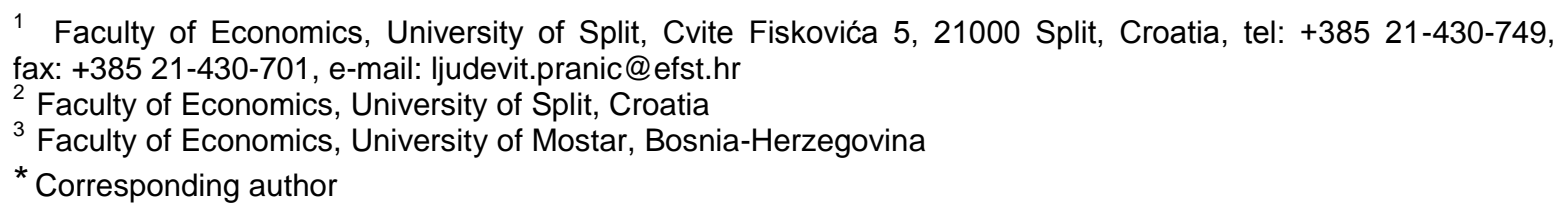

\section{Abstract}

While a growing number of countries and sub-national localities are banning smoking in hospitality workplaces, extant research on the impacts of smoke-free legislation has centered on hospitality employees and industries in developed countries. Hoping to assist in filling this void, this research empirically explores the relationships among café employees' attitudes, demographics, work-related variables (WRV), and job satisfaction before the introduction of a smoke-free legislation in one transition economy, i.e. Bosnia-Herzegovina. Results revealed that café area served, gender, average weekly workload, café seating allocation, and education were for the most part not significant in explaining different perceptions toward a smoking ban. However, respondents' preferred café smoking policy, smoking status, hospitality work experience, job satisfaction, and age did influence how respondents viewed the smoking ban. In terms of respondents' preferred café smoking policy, significant differences were noted due to smoking status and café seating allocation. In regards to job satisfaction, staff with more positive pre-implementation attitudes towards the ban exhibit significantly higher levels of dissatisfaction with the current job. Overall, respondents appear willing to make concessions for both pro- and anti-smoking patrons, staff, and owners/managers. Therefore, lawmakers should consider population characteristics, seating allocation, and the combination thereof when devising café smoking policies.

(C) 2013 International University College. All rights reserved

Keywords: second-hand smoke, smoking ban, attitude, job satisfaction, transition country, employee

Citation: Pranić, L., Pivac, S. \& Čolak, A. (2013). Pre-smoke-ban café staff job satisfaction and attitudes in transition countries. European Journal of Tourism Research 6(1), 5-19.

\section{Introduction}

Healthcare and tobacco research has long established that smoking is not only hazardous to smokers, but also to those exposed to second-hand smoke (SHS; also known as the environmental tobacco smoke [ETS]) in 
Pre-smoke-ban café staff job satisfaction and attitudes in transition countries.

restaurants, bars, offices, and other enclosed spaces where smoking is allowed (National Cancer Institute, 1999; World Health Organization [WHO], 2008, 2011a). Moreover, ETS levels have been found to be 3.9-6.1 times higher in bars, as compared to office workplaces (Siegel, 1993). Armed with evidence that SHS harms the health of customers and employees, many countries and jurisdictions (e.g. U.S., Canada, New Zealand, Australia, Ireland, Italy, Croatia, etc.) have in the past two decades adopted legislation restricting or prohibiting smoking in work-places and public places, such as restaurants and bars. Needless to say, in both past and present attempts to ban smoking in restaurants and bars, many hospitality owners, managers, and associations have put up resistance to a smoking ban, citing rights (as owners) to make their own decisions regarding smoking policies and fears from a decrease in patronage and the associated loss in sales and profits (Hirasuna, 2006; Roseman, 2005).

In response to the often heated debates between public health advocates and smoking ban opponents regarding the economic effects of smoking bans in bars and restaurants, over 150 studies in English language have been conducted on the subject as late as February 2008, as identified by Scollo and Lal (2008). Despite voluminous research, a closer inspection of the 150+ smoke-ban-related research articles comprehensively reviewed by Scollo and Lal reveals the following three gaps in the available research. First, only 36 (22\%) of the smoke-ban-related studies were peer reviewed, with many non-peer reviewed studies sponsored by the tobacco industry (Scollo and Lal, 2008). Second, of the 36 peer reviewed studies, $22(63 \%)$ were conducted in the U.S., followed by Australia (4), Canada (3), New Zealand (3), South Africa (2), UK (1), and Italy (1). Meanwhile, research in transition and developing countries remains scarce. Third, very few research articles about employees' attitudes and job satisfaction toward smoking bans have been published in hospitality journals thus far (Hetland et al., 2008; Pizam, 2012). Indeed, updating the literature on smoking ban issues is important to the hospitality industry and hospitality owners and managers are seeking relevant data that identifies the potential impact smoking bans will have on employees' health, attitudes, and job satisfaction.

The lack of peer reviewed research regarding (1) the effects of smoke-free legislation on the hospitality industry, (2) the impacts on hospitality sectors in transition countries, and (3) employees' job satisfaction and attitudes toward smoke-free legislation in general, form the basis for this study. The additional rationale for this study stems from the relevance and timeliness of employee opinion regarding smoking in hospitality establishments in transition countries. In one transition country, i.e. Bosnia-Herzegovina, the parliament ratified the WHO Framework Convention on Tobacco Control on July 10, 2009 (WHO, 2011b). Consequently, Bosnia-Herzegovina officials are on the verge of introducing the new antismoking regulations that will affect cafés, restaurants, schools, theatres, hospitals, factories, and all government offices.

The main objectives of this exploratory study are to:

$\checkmark$ Assess the profile of Bosnia-Herzegovina café staff;

$\checkmark$ Examine employees' pre-implementation job satisfaction and attitudes towards café smoking ordinances in Bosnia-Herzegovina;

$\checkmark$ Empirically explore whether the reported attitudes are associated with demographics (i.e., gender, education, and age) and workrelated variables ([WRV] i.e., hospitality work experience, average weekly workload, smoking status, preferred café smoking policy, café area served, café seating allocation);

$\checkmark$ Assess the influence of demographics and WRV on café smoking policy;

$\checkmark$ Investigate the effects of demographics, WRV, and attitudes towards a café smoking ban on employee's job satisfaction;

The rest of the paper is organized as follows; we first review the impacts of smoke-free legislation on the hospitality sector. Subsequently, the section covering transition countries helps contextualize the current study. We then describe the methodology employed, followed by a discussion of the results and the study's conclusions and implications. 
Pranić, L., Pivac, S. \& Čolak, A. (2013). European Journal of Tourism Research 6(1), 5-19.

\section{Impacts of Smoke-Free Legislation on the Hospitality Industry}

Through a careful reading of outcome measures presented by Scollo and Lal (2008) in their seminal review of over 150 studies in English language on the effects of smoke-free policies in the hospitality industry, three broad themes appear to emerge - impacts on customers, impacts on owners and managers, and impacts on staff. These impacts are discussed in greater detail in the subsequent sections.

\section{Impacts on customers and owners/managers}

In terms of impacts of smoke-free legislation on hospitality customers, Kang et al. (2007) detected no significant differences on perceptions or dining out behaviours among Colorado college students based on their smoking status. Miller and Hickling (2006) found higher bar patronage and greater impact of the new law on patronage, current smoking, and future likelihood of quitting among young adults (18-24 years) four months into Phase I of the phased-in smoking ban in South Australia. In a study comparing adult smokers in the Republic of Ireland (ROI) and UK (no smoking ban) before and 8-9 months after the ROl's ban, Fong et al. (2006) found that in ROI $35 \%$ of smokers and $16 \%$ of quitters reported avoiding going to pubs, and $18 \%$ of smokers and $8 \%$ of quitters reported avoiding going to restaurants. In a comparison of future dining behaviours among non-smokers, former smokers, and smokers in Kentucky, Roseman (2005) found that non-smokers and former smokers were likely to eat out more, while smokers were more likely to eat out less. Similar findings were revealed in studies of Hong Kong (Lam et al., 2002) and South Australian (Wakefield et al., 1999) restaurant consumers. Tang et al. (2003) employed three cross-sectional surveys to examine bar patrons' attitudes at three months, eight months, and 2.5 years after enactment of the 1998 smoke-free law in California. They found that, over time, California's bar patrons increasingly favoured the smoke-free bar law, took seriously the health concerns regarding exposure to ETS, and complied with the law. Moreover, 2.5 years after the law's enactment, $32.3 \%$ of the respondents reported that they were more likely to visit bars, whereas only $9 \%$ had the opposite opinion.

In terms of smoking ban impacts on hospitality owners and managers, in the longitudinal analysis of the impact of a 2004 smoking ban on restaurant and pub revenues in Norway, Melberg and Lund (2010) did not find any statistically significant effects on Norway's restaurant revenues. However, in pubs, a share of personal consumption revenues went down in the short-run, but in the long-run and in absolute terms revenues increased. Luk et al. (2006) found no significant adverse impact of smoke-free legislation on restaurant and bar sales in a bilingual city of Ottawa. A survey of New Zealand's bar managers showed not only a significant increase in overall support for the smoking legislation after implementation, but also an increased agreement that smoke-free laws do not affect patron numbers and venue profits (Thomson and Wilson, 2006). Alamar and Glantz (2007) found no significant differences in purchase prices between similar bars sold in smoke-free and smoking-permitted U.S. jurisdictions. In a similar study of restaurants, Alamar and Glantz (2004) showed that U.S. restaurants in smoke-free locations sold for higher prices than comparable restaurants in locations where smoking was allowed.

\section{Impacts on staff}

Klein et al. (2009) examined over a 45-month period whether the type of smoking ban (i.e., comprehensive, partial, and no ban) significantly affects employment levels in freestanding bars and full-service restaurants in ten cities in Minnesota. Theirs being the first published, peer-reviewed evaluation on the differential effects of the type of smoking policy on hospitality employment, they found no significant short- or long-term effect on bar and restaurant total employment. In a Norwegian panel study of employee job satisfaction before and after the smoking ban implementation, there was a slight improvement in satisfaction among employees who are non-smokers and a moderate decrease in satisfaction among employees who smoke (Hetland et al., 2008). Also, while post-implementation job satisfaction was higher among employees with positive preimplementation attitudes towards the ban, 
Pre-smoke-ban café staff job satisfaction and attitudes in transition countries.

employees with negative pre-implementation attitudes experienced a decrease in postimplementation satisfaction.

Using employment data from across the various U.S. counties, Adams and Cotti (2007) found that bar employment decreased in communities where smoking was banned compared with those that allowed smoking. However, bar job loss was substantially more pronounced in areas with a high prevalence of smokers. Compared to bars, restaurant employment remained the same, and in areas with fewer smokers, it had even slightly increased. They also argued that the prevalence of restaurant outdoor seating might influence the policy's effect, because they found evidence of increased employment in warmer regions of the country during the cooler winter months, and in the summer in colder regions. Ellingsen et al. (2006) employed a repeated measures design to assess the level of airborne contaminants and staff urinary nicotine levels in 13 bars and restaurants in Oslo, Norway, before and after the implementation of a smoking ban. A substantial reduction of airborne nicotine and total dust was observed after the introduction of a smoking ban compared to the levels when smoking was allowed. While urinary nicotine levels were substantially lower in both smokers and non-smokers following the ban enactment, a significantly larger decrease was found in smokers compared to non-smokers, probably because the ban drove the former to smoke less.

Pilkington et al. (2006) found that non-smoking casino workers in London, UK, were significantly more concerned about health consequences of SHS exposure, more bothered by smoke, and more supportive of smoke-free work areas than their smoking counterparts. However, a significant number of smoking casino employees also wanted smoke-free workplaces. In another study in Norway, Hetland and Aarö (2005a) found that after the ban enactment, hospitality staff benefited from the easier cleaning of premises, a better state of health, better air quality, and work clothes that did not reek of smoke. Research elsewhere further supports the link between the introduction of a total smoke-ban to improvement of respiratory symptoms among bar and restaurant staff (Eisner et al., 1998; Eagan et al., 2006; Skogstad et al., 2006), as well as the indoor air quality (Mulcahy et al., 2005; Ellingsen et al., 2006). Employees in Norway also reported fewer unpleasant incidents and better compliance in enforcing a total smoking ban compared with a previous partial ban (Hetland and Aarö, 2005b).

In a study of standalone and combination bars (i.e., those connected to restaurants, hotels, etc.) in California, Tang et al. (2004) found that employee support for a smoke-free bar law significantly increased shortly after its enactment and four years later. Positive attitudinal changes were observed among both types of bars, with greater changes among standalone bars after the ban introduction. In the state of New York, Hyland et al. (2000) found no statistically significant change in hospitality employment levels following a ban relative to other places in their study. Interestingly, unemployment was slightly higher in restaurants during the winter months, suggesting that climate may play an important role in a law's impact. In Adelaide, Australia, hospitality staff reported concerns about possible bankruptcies and loss of jobs if a smoking ban was to be implemented (Jones et al., 1999). However, among restaurateurs whom voluntarily banned smoking, most reported no change or an increase in business.

\section{Summary}

The preceding short summary of peer-reviewed studies generally supports the view that when a smoking ban is uniform throughout a geographic area (city, state, province, etc.), the industry-level effects of regulation seems nonexistent or even favourable in the area (Alamar and Glantz, 2007, 2004; Luk et al., 2006; Melberg and Lund, 2010; Scollo and Lal, 2008; Thomson and Wilson, 2006). However, on a firm-level, limited research suggests that the moderating effects of establishment type (i.e., restaurants vs. bars), community population characteristics (i.e., high vs. low smoking prevalence), and the combination thereof might influence the impact of smoking bans (Adams and Cotti, 2007; Dunham and Marlow, 2000; Hammar, 2004; Hyland et al., 2000). When it comes to employees and patrons, their 
attitudes and behaviours appear to be largely driven by their smoking status. Hence, employees who are smokers tend to be less satisfied and supportive of smoking prohibitions than their non-smoking colleagues. Similarly, non-smoking patrons are likely to frequent hospitality establishments more often after the ban's enactment, and thus offset the decreased volumes of smoking guests. Ultimately, all three groups unanimously recognize the negative effects of smoking and SHS exposure. Admittedly, some employees and patrons credit smoke-free laws for quitting smoking.

Overall, in the assessment of impacts of smoke-free legislation in the hospitality industry, researchers have employed objective (e.g., data derived from official employment statistics, staff urinary nicotine levels, etc.) and/or subjective (e.g., data obtained via surveys of owners, employees, and patrons of restaurants, bars and other hospitality establishments) data that were collected before and/or after the implementation of a smoking ban (Luk and Ferrence, 2005). Objective data cover all establishments in jurisdictions under consideration and are collected routinely by official or neutral agencies over an extensive period using consistent methods. These data are verifiable and therefore thought to be superior to the subjective perceptions of owners, employees, and consumers (Luk and Ferrence, 2005).

However, studies using objective data have been criticized for relying on community averages (as opposed to firm-level indicators) and revenues (instead of profits; Dunham and Marlow, 2000), and for failing to account for the effect of confounding factors, such as trend, seasonal variation, the general economic conditions and other events that are unrelated to the legislation (Jones et al. 1999; Kang et al., 2007). On the other hand, subjective data, provided they come from the properly designed owner, employee or consumer surveys, can reveal data at the micro level and thus be useful in supplementing studies that use objective data (Luk and Ferrence, 2005). As expected, studies using subjective data have been criticized for relying on unverifiable perceptions that may be biased by personal attitudes toward the smoking ban.
This being said, extant research on the impacts of smoke-free legislation has centred on hospitality employees and industries in developed countries (e.g., Scollo and Lal, 2008), with the most commonly examined localities being those located in the U.S. (Kenkel and Wang, 2008). Meanwhile, much less is known about the impact on hospitality staff in transition and developing countries.

\section{Countries in transition}

The term 'countries in transition' exclusively applies to the former communist countries of Central and Eastern Europe, including the former Soviet Union (United Nations Statistics Division, 2011), that are undergoing a gruelling social, political, and economic transformation from a centrally planned economy to a marketbased one (Goić and Bilić, 2008). This process of transition begun in the late 1980's following the fall of both the Berlin wall and the communist system. During the decades leading to the fall of the Berlin Wall, private-sector entrepreneurship in these countries was restricted, confined, hampered, suppressed, and even illegal (Goić and Bilić, 2008). Furthermore, in 2003 adult smoking stood at $31.5 \%$ (47\% men and 15\% women) among transition nations, compared to $29 \%$ (38\% men and $16 \%$ women) in the rest of the world (Budak et al., 2006). Moreover, the Eastern Europe and Eurasia region is the only region worldwide to have witnessed a population decrease in 1991-2002 (Heinegg et al., 2005). To this extent, from the developed country perspective, all transition countries either went or are still going through similar processes and face or have faced analogous developmental issues, and thus may be considered as relatively homogenous.

Now, after more than 20 years since the onset of the transition era, the free market economy surprisingly still remains an elusive concept in many, albeit not all, aspects of society at large. On a related note, Bosnia-Herzegovina has long enacted legislation against tobacco sale to minors (i.e., <18 year-olds); however, as in other transition nations (Balabanova et al., 1998), the laws are poorly enforced. For example, $89 \%$ of Bosnia-Herzegovina's elementary (i.e., primary) and high (i.e., secondary) school students ages 13-15 who 
Pre-smoke-ban café staff job satisfaction and attitudes in transition countries.

bought cigarettes in a store were not refused purchase because of their age (Centers for Disease Control and Prevention, 2008).

Taken together, these examples suggest that the social fabric in Bosnia-Herzegovina and other transition countries cannot be understood simply by looking at developed and other nontransition countries. Host population's perceptions and behaviours are products of complex and long lasting past processes, and thus take time to change. In fact, a business culture in the transition countries cannot be explained exclusively either by their communist heritage or by their journey through transformation. Therefore, the process of introducing modern market mechanics into Central and Eastern European transition countries continues with a specific task of significantly altering the host population's social, economic, political, and environmental attitudes and behaviours.

With these ideas in mind, it appears important to understand how smoke-free laws affect the hospitality industries in transition countries such as Bosnia-Herzegovina. Through an empirical assessment of employees' preimplementation attitudes toward BosniaHerzegovina's partial smoking ban in cafes and their knowledge concerning ban regulations, this article seeks to make a contribution in the needed direction.

\section{Methodology}

This study featured a primary data collection, whereby a two-page anonymous selfadministered questionnaire written in Croatian was administered to café employees in BosniaHerzegovina's third largest city (Mostar). The sampling frame for this study comprised all staff employed in 55 cafés, where the latter was obtained from the yellow pages of $\mathrm{BH}$ Telecom (2010) and HT Eronet (2011), and cross checked with their online databases. A group of trained students helped by personally delivering the first (baseline) paper survey and recruiting café employees (owners, managers, and assistant managers excluded) to partake in survey completion. The questionnaires were either completed on the spot or picked-up at a pre-agreed later time. For those cafés where employees either failed or initially refused to complete the questionnaire, two additional attempts were made in hopes of reminding or recruiting another employee to complete the task.

The majority of survey questions were borrowed from Biener and Siegel (1997), Brayfield and Rothe, (1951), Cameron et al. (2003), Fong et al. (2006), Hetland and Aaro (2005a), Judge et al. (2001), Kang et al. (2007), Miller and Hickling (2006), Roseman (2005), Tang et al. (2003), and Wan and Pilkington (2009), and adapted to this study's context. Since smoking ban can potentially influence drinking habits of both smoking and non-smoking patrons (Room, 2005), two Likert scale items were developed in order to examine employees' anticipated changes in patron alcohol and coffee consumption after the law's enactment.

The questionnaire was composed of three sections. The first section measured respondents' demographics (i.e., gender, education, and age), hospitality work experience, average weekly workload, smoking status, preferred café smoking policy, café area served, and café seating allocation. The second section measured respondents' preimplementation perceptions of a café smoking ban, using a 24-item five-point Likert scale anchored by 1 (strongly disagree) and 5 (strongly agree). Therein, several items were reverse-worded to reduce the danger of response bias (Churchill, 1979; Nunnally, 1978). Section three measured respondents job satisfaction using a 5-item, five-point Likerttype job satisfaction index (Brayfield \& Rothe, 1951; Hetland \& Aaro, 2005a; Judge et al., 2001). Questionnaire design followed the established survey guidelines (Fanning, 2005; Dillman, 2000) and was evaluated by two social science research experts. The subsequent pretest of the instrument on 10 café employees revealed only a few typos that were easily corrected.

Descriptive statistics included frequency analysis of all variables. The differences in expressed pre-implementation attitudes towards a café smoking ban regarding the demographics and WRV were tested by the non-parametric Kruskal-Wallis (K-W) and 
Pranić, L., Pivac, S. \& Čolak, A. (2013). European Journal of Tourism Research 6(1), 5-19.

Mann-Whitney $\mathrm{U}(\mathrm{M}-\mathrm{W} \mathrm{U})$ tests. The influence of demographics and WRV on preferred café smoking policy was examined via a series of Chi-square $\left(x^{2}\right)$ tests. The effects of demographics, WRV, and attitudes towards a café smoking ban on employee's job satisfaction were also examined through a series of Chi-square tests. P-value less than 0.05 was considered as the evidence of statistical significance.

Measure of internal consistency (reliability) of both job satisfaction and attitudinal scales was calculated using Cronbach's alpha coefficient (Carmines and Zeller, 1979; Cook and
Campbell, 1979). Agglomerative hierarchical cluster analysis of the 24-item attitudinal scale was performed to explore the scale's underlying dimensions.

\section{Findings and discussion}

Respondent profile

Of the 153 respondents, $41 \%$ were female and $59 \%$ male (Table 1). Just over half of the respondents (52\%) worked 0-5 years in any type of hospitality establishment, followed by 6 10 years (29\%), $11-15$ years (16\%), and $>16$ years (3\%). Majority (43\%) worked 41-48 hours/week on average, followed by $\geq 49$ (36\%) and $\leq 40(21 \%)$ hours/week.

Table 1. Respondent profile

\begin{tabular}{|c|c|c|}
\hline Variable & Number & Valid \% \\
\hline \multicolumn{3}{|l|}{ Gender $(n=151)$} \\
\hline Male & 89 & 58.9 \\
\hline Female & 62 & 41.1 \\
\hline \multicolumn{3}{|l|}{ Age $(n=153)$} \\
\hline $16-24$ & 53 & 34.6 \\
\hline $25-34$ & 82 & 53.6 \\
\hline $35-44$ & 16 & 10.5 \\
\hline$\geq 45$ & 2 & 1.4 \\
\hline \multicolumn{3}{|l|}{ Education attained $(n=149)$} \\
\hline High school & 95 & 63.8 \\
\hline Bachelor's degree or higher & 54 & 36.2 \\
\hline \multicolumn{3}{|l|}{ Hospitality work experience in years $(n=153)$} \\
\hline $0-5$ & 79 & 51.6 \\
\hline $6-10$ & 45 & 29.4 \\
\hline $11-15$ & 24 & 15.7 \\
\hline$\geq 16$ & 5 & 3.3 \\
\hline \multicolumn{3}{|l|}{ Average weekly workload in h/week $(n=151)$} \\
\hline$\leq 40$ & 32 & 21.2 \\
\hline $41-48$ & 65 & 43.0 \\
\hline$\geq 49$ & 54 & 35.8 \\
\hline \multicolumn{3}{|l|}{ Smoking status $(n=153)$} \\
\hline Full-time smoker & 88 & 57.5 \\
\hline Occasional smoker & 29 & 19.0 \\
\hline Former smoker & 12 & 7.8 \\
\hline Never smoked & 24 & 15.7 \\
\hline \multicolumn{3}{|l|}{ Preferred café smoking policy $(n=152)$} \\
\hline Ban smoking everywhere & 23 & 15.1 \\
\hline Allow smoking everywhere & 51 & 33.6 \\
\hline Allow smoking in outdoor area only (e.g. on the patio) & 13 & 8.6 \\
\hline Allow smoking in designated indoor area only & 23 & 15.1 \\
\hline Allow smoking in outdoor and designated indoor areas only & 38 & 25.0 \\
\hline Other & 4 & 2.6 \\
\hline \multicolumn{3}{|c|}{ While at work, you spend majority of your time (i.e., café area served; $n=135$ ) } \\
\hline Indoors & 126 & 93.3 \\
\hline Outdoors & 9 & 6.7 \\
\hline \multicolumn{3}{|l|}{ Café seating allocation $(n=153)$} \\
\hline Majority outdoors & 9 & 5.9 \\
\hline Majority indoors & 60 & 39.2 \\
\hline About the same both outdoors and indoors & 84 & 54.9 \\
\hline
\end{tabular}


Nearly two-thirds (64\%) were high school graduates, while $36 \%$ held an associate's degree or higher. The latter figure can be explained by the very high unemployment rate $(43 \%)$ in Bosnia-Herzegovina (Central Intelligence Agency [CIA], 2012). In terms of age, $54 \%$ were in the $25-34$ age group followed by $16-24$ year-olds (35\%), 35-44 year-olds $(10 \%)$, and those 45 and older (1\%). As for respondents' smoking status, $57 \%$ were fulltime smokers, followed by occasional smokers (19\%), non-smokers (16\%), and former smokers $(8 \%)$. Interestingly, the percentage of full-time smokers in this study's sample is

Table 2. The relationship among smoke ban attitudes, demographics, WRV, and job satisfaction

\begin{tabular}{|c|c|c|c|c|c|c|c|c|c|c|c|}
\hline $\mathrm{V}^{\prime}$ & $M^{\prime \prime}$ & $\mathrm{G}^{\mathrm{III}}$ & $A^{I V}$ & $E^{I I I}$ & $\mathrm{H}^{\mathrm{IV}}$ & $\mathrm{W}^{\mathrm{IV}}$ & $\mathrm{S}^{\mathrm{IV}}$ & $\mathrm{P}^{\mathrm{IV}}$ & $\mathrm{C}^{\mathrm{III}}$ & $S A^{I V}$ & $\mathrm{~J}^{\mathrm{III}}$ \\
\hline $1^{v}$ & 3 & 0.762 & $0.001^{\prime \prime 30}$ & 0.244 & $0.003^{m 10}$ & 0.179 & $0.002^{n " F}$ & 0.000 & 0.409 & 0.601 & 0.168 \\
\hline 2 & 4 & 0.092 & $0.019^{* 30}$ & 0.712 & $0.012^{* 10}$ & 0.256 & $0.000^{* * *} \mathrm{~F}$ & $0.000^{* * *} B$ & 0.417 & 0.924 & 0.721 \\
\hline 3 & 3 & 0.806 & 0.906 & 0.242 & 0.466 & 0.512 & 0.674 & 0.717 & 0.365 & 0.639 & 0.096 \\
\hline 4 & 4 & 0.321 & 0.869 & 0.821 & 0.067 & 0.725 & 0.734 & 0.089 & 0.342 & $0.009^{* * O}$ & 0.862 \\
\hline 5 & 2 & 0.118 & 0.775 & $0.012^{* H}$ & 0.253 & 0.083 & 0.913 & 0.150 & 0.114 & 0.211 & $0.024^{* \mathrm{D}}$ \\
\hline 6 & 3 & 0.975 & 0.604 & 0.791 & 0.977 & 0.751 & $0.008^{* * D}$ & $0.000^{* * *} \mathrm{~A}$ & 0.863 & 0.687 & 0.387 \\
\hline 7 & 4 & $0.041^{*} \mathrm{~F}$ & $0.048^{* 20}$ & 0.499 & $0.050^{* 5}$ & 0.820 & 0.060 & $0.002^{* \star A}$ & 0.870 & 0.880 & 0.110 \\
\hline 8 & 3 & 0.510 & 0.169 & $0.009^{x \times H}$ & 0.435 & $0.048^{49}$ & 0.871 & 0.467 & 0.295 & 0.091 & 0.756 \\
\hline 9 & 3 & 0.345 & 0.200 & 0.500 & 0.289 & 0.071 & $0.002^{\pi \times U}$ & 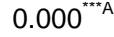 & 0.110 & 0.521 & $0.026^{* \mathrm{~S}}$ \\
\hline 10 & 4 & $0.005^{\text {nז }}$ & 0.438 & 0.059 & 0.202 & 0.694 & 0.631 & 0.309 & 0.064 & $0.012^{\star U}$ & 0.123 \\
\hline 11 & 3 & 0.383 & 0.563 & $0.034^{* A}$ & 0.081 & 0.717 & $0.037^{* \mathrm{D}}$ & $0.003^{* * A}$ & $0.022^{* 0}$ & 0.065 & 0.731 \\
\hline 12 & 3 & $0.045^{\text {xt }}$ & $0.025^{\times 30}$ & 0.200 & $0.022^{* 10}$ & 0.094 & $0.000^{\pi \times r}$ & $0.000^{x \times B}$ & 0.945 & 0.963 & $0.001^{\times x}$ \\
\hline 13 & 2 & 0.301 & 0.220 & $0.044^{\mathrm{xH}}$ & $0.035^{\times 10}$ & 0.951 & $0.043^{x}$ & $0.013^{x}$ & 0.844 & 0.870 & $0.003^{x \times L}$ \\
\hline 14 & 2 & 0.992 & 0.237 & 0.612 & 0.293 & 0.382 & $0.003^{\pi \times U}$ & $0.001^{\times × \mathrm{~B}}$ & 0.624 & 0.371 & $0.001^{\times x}$ \\
\hline 15 & 4 & 0.250 & 0.078 & 0.511 & $0.002^{* \star 5}$ & 0.112 & 0.401 & 0.205 & 0.182 & 0.559 & $0.010^{* \mathrm{D}}$ \\
\hline 16 & 2 & 0.059 & $0.012^{* 30}$ & 0.431 & $0.003^{* * 10}$ & 0.124 & $0.000^{* * *} F$ & $0.000^{* * *} B$ & 0.750 & 0.165 & 0.065 \\
\hline 17 & 3 & 0.249 & $0.005^{\times 30}$ & $0.043^{\mathrm{KH}}$ & $0.011^{\pi 10}$ & 0.102 & $0.032^{\text {* }}$ & $0.000^{x \times b}$ & 0.968 & 0.150 & $0.010^{*}$ \\
\hline 18 & 4 & 0.096 & $0.004^{* * 20}$ & 0.892 & $0.009^{* * 5}$ & 0.384 & 0.295 & $0.020^{* B}$ & 0.202 & 0.575 & 0.343 \\
\hline 19 & 3 & 0.597 & $0.004^{* * 20}$ & 0.216 & $0.002^{* * 5}$ & 0.635 & $0.001^{* *} \mathrm{~F}$ & $0.000^{* * * B}$ & 0.646 & 0.595 & 0.183 \\
\hline 20 & 3 & 0.352 & 0.139 & 0.187 & $0.042^{* 10}$ & $0.023^{* 49}$ & $0.000^{* * *}$ & $0.000^{\star * * B}$ & 0.292 & $0.047^{* \mathrm{~A}}$ & $0.026^{\star *} \mathrm{C}$ \\
\hline 21 & 3 & 0.943 & 0.145 & 0.539 & 0.386 & $0.005^{* * 44}$ & $0.041^{*} \mathrm{~N}$ & 0.431 & 0.184 & 0.559 & 0.243 \\
\hline 22 & 3 & 0.385 & 0.710 & 0.350 & 0.536 & $0.008^{* * 44}$ & 0.119 & $0.001^{\star *} \mathrm{D}$ & 0.663 & 0.165 & 0.449 \\
\hline 23 & 5 & 0.948 & 0.993 & 0.277 & 0.758 & 0.164 & 0.897 & 0.531 & 0.579 & $0.002^{* \star A}$ & $0.033^{* \mathrm{D}}$ \\
\hline 24 & 3 & 0.153 & 0.173 & $0.006^{* * H}$ & $0.014^{* 10}$ & 0.143 & $0.039^{* \mathrm{~N}}$ & $0.012^{* B}$ & 0.835 & 0.071 & 0.067 \\
\hline 25 & 3 & 0.433 & 0.344 & $0.023^{* A}$ & 0.155 & 0.063 & 0.771 & 0.443 & 0.373 & 0.490 & \\
\hline
\end{tabular}

'Variables (groups with the highest average ranks are in parentheses): $G=$ gender ( $F=$ female); $A=a g e ~(20=16-24$ years;

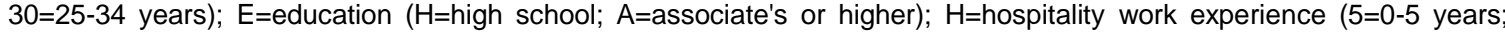
$10=6-10$ years); $W=$ average weekly workload $(44=41-48 \mathrm{~h} / \mathrm{wk} ; 49=\geq 49 \mathrm{~h} / \mathrm{wk}) ; \mathrm{S}=$ smoking status ( $D=$ full-time smoker; $\mathrm{O}=$ occasionally; $\mathrm{F}=$ former smoker; $\mathrm{N}=$ never smoked); $\mathrm{P}=$ preferred café smoking policy $(\mathrm{B}=$ ban; $\mathrm{A}=$ allow; $\mathrm{D}=\mathrm{allow}$ in designated areas); $\mathrm{C}=$ café area served $(\mathrm{O}=$ outdoor); $\mathrm{SA}=$ seating allocation $(\mathrm{O}=$ majority outdoors; $\mathrm{A}=$ about the same indoors and outdoors); $\mathrm{J}=\mathrm{job}$ satisfaction ( $\mathrm{S}=$ satisfied [answers 4 \& 5 on a 5 -point Likert-type index anchored by ' $1=$ strongly disagree' and ' $5=$ strongly

agree']; $D=$ dissatisfied [answers 1-3 on the same scale]).

ii Because of dataset's high dispersion (coefficient of variation $V>.30$ ), mean is not a valid measure of central tendency, and median is used instead.

iii Mann-Whitney $U(M-W U)$ test.

iv Kruskal- Wallis (K-W) test. " $p<.05 ;{ }^{* *} p<.01 ;{ }^{* * *} p<.001$.

${ }$ 1. It is more pleasant to visit cafés with full or partial smoke ban; 2 . Impending law [IL] is necessary to protect staff health; 3. IL will encourage smokers to quit; 4. IL will negatively impact café business; 5 . IL will result in increased café patronage; 6. IL will negatively affect staff; 7 . Smokers will visit cafés with full or partial smoking allowed more often after the IL's enactment; 8. Non-smokers will visit cafés with full or partial smoking ban more often after the IL's enactment; 9 . IL is unfair to smokers; 10. Smokers will smoke at home more often after the IL's enactment; 11. IL will bring about job loss; 12. I support the IL banning smoking in cafés; 13. I will seek a smoke-free workplace in the future; 14. I consider it important to find a job with a smoke-free employer; 15. I'm frequently exposed to workplace SHS; 16. I'm bothered by others who smoke near me; 17. I'm concerned about the consequences of SHS on my health; 18. SHS is hazardous; 19. IL will improve the quality of life; 20 . Smoking should be banned in cafés; 21 . Patrons will drink less alcohol in cafés after the IL's enactment; 22. Patrons will drink less coffee in cafés after the IL's enactment; 23. It will be very difficult to implement the IL; 24 . Café patrons will react very favorably to the IL; 25 . Mean job satisfaction comprised of the following five items (I. I feel fairly satisfied with my present job; II. Most days I am enthusiastic about my work; III. Each day at work seems like it will never end; IV. I find real enjoyment in my work; V. I consider my job to be rather unpleasant). 
Pranić, L., Pivac, S. \& Čolak, A. (2013). European Journal of Tourism Research 6(1), 5-19.

slightly higher than that of U.S. bartenders (55.49\%; Pizam, 2012). Moreover, in comparison to our sample, $38 \%$ of BosniaHerzegovina's adults (i.e., 18+) are smokers (Bosnia and Herzegovina Federal Office of Statistics, 2011).

When asked about their preferred type of café smoking policy, $34 \%$ of the respondents indicated that smoking should be allowed in all guest areas, followed by both outdoor and designated indoor areas (25\%), designated indoor area only (15\%), outdoor area only (9\%), full smoking ban (15\%), and other (2\%). While at work, an overwhelming majority (93\%) of the respondents spend most of their time indoors, as opposed to an outdoor patio (7\%). In terms of café seating allocation, $55 \%$ of cafés have an equal share of indoor and outdoor seating, followed by cafés with majority indoor (39\%) and majority outdoor (6\%) seating.

\section{Job satisfaction and attitudes towards a smoke ban}

Because of our dataset's high dispersion (coefficient of variation $V>0.30$ ), respondents' answers are indicated by the median level of agreement with the five job satisfaction and 24 attitude items (Table 2). Accordingly, café employees generally are neither satisfied nor dissatisfied with their jobs. In terms of staff attitudes towards the ban, subjects reported the highest agreement with the following seven statements: "The imminent café smoking ban will be very hard to implement", "the impending law is necessary to protect staff's health", "the approaching law will negatively impact café business", "following the ban's implementation, smokers will frequent partially or fully smokefriendly cafés more often", "following the ban, smokers will smoke at home more often", "I'm frequently exposed to other people's smoke in cafés", and "passive smoking is harmful." Participants indicated lowest degree of agreement with the statements "the imminent smoking ban will increase my café's patronage", "I will seek a smoke-free workplace in the future", "I consider it important to find a job with a non-smoking employer", and "I'm bothered by others who smoke near me". Again, disagreement with the middle two statements can be explained by both BosniaHerzegovina's $43 \%$ unemployment rate (CIA, 2012) and the high ratio (i.e., $76 \%$ ) of full-time and occasional smokers in our sample.

The effects of demographics and WRV on smoke ban attitudes

For the 24-item attitudinal scale, the average linkage between groups clustering produced a two cluster solution (Friedman test $\mathrm{X} 2$, $\mathrm{p}<0.001$ ) with a 10 -item and 14 -item clusters (Table 3). The two scales achieved an acceptable 0.70 and 0.86 Cronbach's Alpha (Nunnally, 1978), respectively.

Specifically, café staff showed statistically higher degree of agreement with the following statements (cluster 1): "The approaching law will negatively impact café business", "the imminent law will negatively impact café staff", "smokers will visit cafés with full or partial smoking allowed more often after the law's enactment", "the impending law is unfair to smokers", "smokers will smoke at home more often after the ban's enactment", "the approaching law will bring about job loss", "I'm frequently exposed to café SHS", "guests will drink less alcohol in cafés after the ban's enactment", "guests will drink less coffee in cafés after the ban's enactment", and "it will be very difficult to implement the approaching ban". Statistically lower degree of café staff

Table 3. Clustering output for the 24 attitudinal items

\begin{tabular}{lc}
\hline Clusters' $^{\text {i }}$ & Mean rank \\
\hline Cluster 1: (Items 4", 6, 7, 9, 10, 11, 15, 21, 22, 23) & 1.68 \\
Cluster 2: (Items 1, 2, 3, 5, 8, 12, 13, 14, 16, 17, 18, 19, 20, 24) & 1.32 \\
\hline 'Friedman test X',$p<0.001$ & \\
"For detailed description, please refer to the footnote ${ }^{\vee}$ in Table 2. &
\end{tabular}


Pre-smoke-ban café staff job satisfaction and attitudes in transition countries.

agreement is with the remaining statements (cluster 2). Generally, the attitudes of café employees towards the imminent café smoking ban are not overly positive.

The application of $\mathrm{K}-\mathrm{W}$ and $\mathrm{M}-\mathrm{W} \mathrm{U}$ tests in order to detect the effects of respondent demographics and WRV on smoke ban attitudes indicates very few significant differences in regards to café area served, gender, average weekly workload, and café seating allocation (Table 2). However, the greatest number of significant differences was noted due to café smoking policy, smoking status, and hospitality work experience.

For instance, former smokers with a 6-10 year hospitality experience and favouring a full ban on smoking - as compared to their counterparts - find it significantly more pleasant to visit cafés with full or partial smoke ban, hold significantly stronger beliefs that the impending smoke-free legislation is necessary to protect staff's health, are significantly more supportive of the imminent café smoke-free law, are significantly more bothered by SHS, are significantly more concerned about the possible health consequences from SHS, and hold significantly stronger belief that smoking should be banned in cafés. For brevity, other significant results in Table 2 are not further elaborated here; however they should be interpreted in a similar fashion.

The effects of demographics and WRV on café smoking preferences

In terms of respondents' preferred café smoking policy, Chi-square tests revealed significant differences due to smoking status and café seating allocation. There were no significant differences in regards to demographics, hospitality work experience, average weekly workload, and café area served. In terms of smoking status, former smokers support a full smoking ban, whereas full-time smokers, occasional smokers, and non-smokers would allow smoking in certain designated areas $\left(x^{2}, \quad p<0.001\right)$. Perhaps former smokers are all too aware of dangers from SHS and, having smoked previously, feel that partial smoke ban is somewhat of an oxymoron, much like partially quitting smoking. As for the café seating allocation, employees in cafés with majority indoor seating do not favour a full smoke ban, while $22 \%$ of staff in cafés with an equal share of indoor and outdoor seating favour a full smoke ban $\left(x^{2}, p=0.006\right)$. Perhaps the latter feel self-assured that smokers will migrate to the café's outdoor seating area, while the former fear smokers will have no choice but to leave such cafés permanently.

The effects of demographics, WRV, and attitudes on job satisfaction

The 5-item job satisfaction scale achieved an acceptable .72 Alpha Coefficient (Nunnally, 1978). K-W and M-W U $p$ values in the bottommost row of Table 2 reveal that the employee job satisfaction significantly varies solely by education. Respondents with an associate's / bachelor's degree or higher exhibit noticeably higher job satisfaction, as compared to those with a high school degree. Perhaps BosniaHerzegovina's 43\% unemployment rate (CIA, 2012) may explain these differences (i.e., even those with college degrees can hardly obtain jobs)

$\mathrm{M}-\mathrm{W} \cup p$ values in the rightmost column of Table 2 unveil that dissatisfied employees show statistically higher degree of agreement with the following statements: "The impending law will result in increased café patronage", "I support the approaching café smoke ban", "I will seek a smoke-free workplace in the future", "I consider it important to find a job with a smoke-free employer", "I'm frequently exposed to café SHS", "I'm concerned about the consequences of SHS on my health", "smoking should be banned in cafés", "it will be very difficult to implement the proposed ban". Satisfied employees, on the other hand, feel strongly that the imminent ban is unfair to smokers. These findings suggest that - once the smoke ban is enacted in BosniaHerzegovina - it may well be that the postimplementation job satisfaction will be higher among employees with positive preimplementation attitudes towards the ban, which is exactly what happened in Norway (Hetland et al., 2008).

\section{Conclusion}

This study empirically profiled BosniaHerzegovina's café employees and examined 
Pranić, L., Pivac, S. \& Čolak, A. (2013). European Journal of Tourism Research 6(1), 5-19.

their pre-implementation attitudes towards a café smoke ban. It also investigated the relationships among demographic characteristics, WRV, attitudes, and job satisfaction. Since for café owners and managers in some countries (i.e., BosniaHerzegovina) the attitudes and satisfaction of current/prospective employees are important, and very little is known about staff attitudes and job satisfaction in Bosnia-Herzegovina and other transition countries, it is believed that results of the current study have theoretical and managerial implications.

While café area served, gender, average weekly workload, café seating allocation, and education were for the most part not significant in explaining different perceptions toward a smoking ban, respondents' preferred café smoking policy, smoking status, hospitality work experience, job satisfaction, and age did influence how respondents viewed the smoking ban. Results revealed that most respondents are generally aware of the dangers of café SHS; however majority favour a 'compromise' outcome instead of either of the two extremes, i.e. banning smoking completely or allowing smoking everywhere. That is, majority of respondents advocate designating outdoor and/or indoor café smoking areas; therefore they appear willing to make concessions to both pro- and anti-smoking patrons, staff, and owners/managers. This finding suggests that lawmakers should consider population characteristics (i.e., high smoking prevalence), seating allocation (i.e., high proportion of café outdoor seating), and the combination thereof when devising café smoking policies.

The current study was limited to café employees in Bosnia-Herzegovina before the approaching smoke ban. Thus, future research should involve restaurant staff and comparisons should be made between café and restaurant personnel. More research is also necessary to determine patrons' and owners'/managers' perceptions of the smokefree ordinances, both in Bosnia-Herzegovina and other transition economies. After the enactment of a smoke-free legislation in Bosnia-Herzegovina and other transition countries, future studies should revisit the issue of the effects of smoke-free laws in the hospitality industry. Similarly, hospitality owners and managers in these countries should be queried to see what kind of challenges they are encountering or have encountered during the changes or to identify how they comply with the smoking regulations.

Another potential limitation of this study lies in the number of response categories used to capture the respondent hospitality work experience and average weekly workload. While this study's question regarding the hospitality work experience includes a '0-5 years' response category, future studies should consider breaking this down further. Namely, the difference between working one month and five years in the industry and forming attitudes on smoking may be substantial. Similarly, in terms of the average weekly workload, attitudes towards smoking may differ significantly between a part-time and full-time employee. Also, future studies should consider defining what is meant by full-time and occasional smoking status. Since validity is an incremental build-up of information from various studies dealing with the concept of scientific inquiry (Anastasi, 1976), future research on smoke-free legislation in cafés and other hospitality contexts will serve to enhance and empirically validate or invalidate the research instrument used in this study.

\section{References}

Adams, S., \& Cotti, C. D. (2007). The effect of smoking bans on bars and restaurants: an analysis of changes in employment. The B.E. Journal of Economic Analysis \& Policy, 7(1), 1-32.

Alamar, B. C., \& Glantz, S. A. (2007). Effect of smoke-free laws on bar value and profits. American Journal of Public Health, 97(8), 1400-1402.

Alamar, B. C., \& Glantz, S. A. (2004). Smokefree ordinances increase restaurant profit and value. Contemporary Economic Policy, 22(4), 520-525.

Balabanova, D., Bobak, M., McKee, M. (1998). Patterns of smoking in Bulgaria. Tobacco Control, 7, 383-385.

Biener, L., \& Siegel, M. (1997). Behavior intentions of the public after bans on smoking in restaurants and bars. 
Pre-smoke-ban café staff job satisfaction and attitudes in transition countries.

American Journal of Public Health, 87(12), 2042-2044.

Bosnia and Herzegovina Federal Office of Statistics. (2011). Statistical yearbook 2011. Retrieved from http://www.fzs.ba/Godisnjak2011.pdf.

Bratonja Martinović, L. (2011, June 7). Broj kafića s dozvolom za pušenje od početka godine popeo se za još 800 . Novi List.

Brayfield, A. H., \& Rothe, H. F. (1951). An index of job satisfaction. Journal of Applied Psychology, 35, 307-311.

Budak, J., Goel, R. K., \& Nelson, M. A. (2006). Smoking prevalence and antismoking regulations in transition countries. Transition Studies Review, 13(1), 231248.

Cameron, M., Wakefield, M., Trotter, L., \& Inglis, G. (2003). Exposure to secondhand smoke at work: A survey of members of the Australian Liquor, Hospitality and Miscellaneous Workers Union. Australian and New Zealand Journal of Public Health, 27(5), 496501.

Carmines, E. G., \& Zeller, R. A. (1979). Reliability and validity assessment. Thousand Oaks: Sage Publications.

Centers for Disease Control and Prevention. (2008). Bosnia and Herzegovina global youth tobacco survey. URL: http://apps.nccd.cdc.gov/gtssdata/Ancill ary/DataReports.aspx?CAID =1 (Accessed on 13/09/2012).

Central Intelligence Agency. (2012). The world factbook - economy: Bosnia and Herzegovina. URL: https://www.cia.gov/library/publications/ the-world-factbook/geos/bk.html (Accessed on 13/09/2012).

Churchill, G. A., Jr. (1979). A paradigm for developing better measures of marketing constructs. Journal of Marketing Research, 16(1), 64-73.

Cook, T. D., \& Campbell, D. T. (1979). Quasi experimentation: Design and analytical issues for field settings. Chicago: Rand McNally.

Corsun, D. L., Young, C. A., \& Enz, C. A. (1996). Should NYC's restaurateurs lighten up? Cornell Hotel and
Restaurant Administration Quarterly, 37(2), 25-33.

Cremieux, P-Y., \& Oullette, P. (2001). Actual and perceived impacts of tobacco regulation on restaurants and firms. Tobacco Control, 10, 33-37.

Cuthbert, L., \& Nickson, D. (1999). Smoking in the restaurant industry: Time for ban? International Journal of Contemporary Hospitality Management, 11(1), 31-36.

Dillman, D. (2000). Constructing the questionnaire: Mail and internet surveys. New York: John Wiley \& Sons.

Dunham, J., \& Marlow, M.L. (2000). Smoking laws and their differential effects on restaurants, bars, and taverns. Contemporary Economic Policy, 18(3), 326-333.

Eagan, T. M., Hetland, J., \& Aaro, L. E. (2006). Decline in respiratory symptoms in service workers five months after a public smoking ban. Tobacco Control, 15, 242-246.

Eisner, M. D., Smith, A. K., \& Blanc, P. D. (1998). Bartenders' respiratory health after establishment of smoke-free bars and taverns. Journal of the American Medical Association, 280(22), 19091914.

Ellingsen, D. G., Fladseth, G., Daae, H. L., Gjolstad, M., Kjaerheim, K., Skogstad, M., Olsen, R., Thorud, S., \& Molander, P. (2006). Airborne exposure and biological monitoring of bar and restaurant workers before and after the introduction of a smoking ban. Journal of Environmental Monitoring, 8, 362368.

European Bank for Reconstruction and Development. (2006). Law in transition online 2006 - focus on central Europe. URL:

http://www.ebrd.com/downloads/resear ch/law/ lit062.pdf (Accessed on 13/09/2012).

Fanning, E. (2005). Formatting a paper-based survey questionnaire: Best practices. Practical Assessment, Research \& Evaluation, 10(12), 1-14.

Fong, G. T., Hyland, A., Borland, R., Hammond, D., Hastings, G., McNeill, A., Anderson, S., Cummings, K. M., Allwright, S., Mulcahy, M., Howell, F., 
Pranić, L., Pivac, S. \& Čolak, A. (2013). European Journal of Tourism Research 6(1), 5-19.

Clancy, L., Thompson, M. E., Connolly, G., \& Driezen, P. (2006). Reductions in tobacco smoke pollution and increases in support for smoke-free public places following the implementation of comprehensive smoke-free workplace legislation in the Republic of Ireland: findings from the ITC Ireland/UK Survey. Tobacco Control, 15(Suppl. III), iii51-iii58.

Goić, S., \& Bilić, I. (2008). Business culture in Croatia and some countries in transition. Management, 13(2), 41-63.

Hammar, H. (2004). Restaurant owner perceptions of the effects of a smoking ban. Health Policy, 70, 243-254.

Hearns, N. (2004). Statutory smoking bans and tourism destinations: Opportunity or threat? Tourism and Hospitality Planning \& Development, 1(3), 195200.

Heinegg, A., Melzig, R., Pickett, J., \& Sprout, R. (2005). Demography and health in Eastern Europe and Eurasia (Working Paper Series on the Transition Countries No. 1). U.S. Agency for International Development. URL: http://www.usaid.gov/ locations/europe_eurasia/wp/wp1_dem ography_health_june_2005.pdf (Accessed on $15^{\text {th }}$ January 2011).

Hetland, J., \& Aaro, L.E. (2005a). Smokefree restaurants and pubs: air quality, self reported health and job satisfaction. URL:

http://www.sirus.no/filestore/Import ved legg/SIRUSskrifter0305eng.pdf

(Accessed on 19th January 2012).

Hetland, J., \& Aaro, L.E. (2005b). Smoking habits, attitudes to and enforcement of the ban on smoking in eating and drinking establishments - a prospective panel study. URL: http://www.sirus.no/filestore//mport_ved legg/Smoking_habits_atti_0305.pdf (Accessed on 19th January 2012).

Hetland, J., Hetland, H., Mykletun, R. J., Aaro, L. E., \& Matthiesen, S. B. (2008). Employees' job satisfaction after the introduction of a total smoke-ban in bars and restaurants in Norway. Health Promotion International, 23(4), 302310.
Hirasuna, D. (2006). Review of economic studies on smoking bans in bars and restaurants (Minnesota House of Representatives Information Brief). URL:

http://www.house.leg.state.mn.us/hrd/p ubs/smokeban.pdf (Accessed on 13/09/2012).

Hyland, A., Vena, C., Cummings, K., \& Lubin, A. (2000). The effect of the clean air act of Erie County, New York on restaurant employment. Journal of Public Health Management and Practice, 6, 76-85.

Igbaria, M., \& Guimaraes, T. (1999). Exploring differences in employee turnover intentions and its determinants among telecommuters and nontelecommuters. Journal of Management Information Systems, 16(1), 147-164.

Jones, K., Wakefield, M., \& Turnbull, D. A. (1999). Attitudes and experiences of restaurateurs regarding smoking bans in Adelaide, South Australia. Tobacco Control, 8, 62-66.

Judge, T. A., Parker, S., Colbert, A. E., Heller, D., \& llies, R. (2001). Job satisfaction: A cross-cultural review. In D. S. Anderson, H. K. S. Ones, \& C. Vieswesvaran (Eds.), Handbook of work and organizational psychology, volume 2 (pp. 25-52). London: Sage Publications.

Kang, S. K., Wie, S., \& Smith, K. (2007). College students' perceptions of a smoking ban in restaurants and bars. Journal of Foodservice Business Research, 10(3), 57-72.

Kenkel, D. S., \& Wang, H. (2008, June). Impact of restaurant smoking bans on demand for smoking and restaurant food. Paper presented at the 2nd Biennial Conference of the American Society of Health Economists, Duke University, NC. URL: http://nzae.org.nz/wpcontent/uploads/2011/08/nr121513826 9.pdf (Accessed on 13/09/2012).

Klein, E. G., Forster, J. L., Erickson, D. J., Lytle, L. A., \& Schillo, B. (2009). Does the type of CIA policy significantly affect bar and restaurant employment in Minnesota cities? Prevention Science, 10, 168-174. 
Kuo, C-M. (2007). The importance of hotel employee service attitude and the satisfaction of international tourists. The Service Industries Journal, 27(8), 1073-1085.

Lam, T. H., Janghorbani, M., Hedley, A. J., Ho, S. Y., McGhee, S. M., \& Chan, B. (2002). Public opinion on smoke-free policies in restaurants and predicted effect on patronage in Hong Kong. Tobacco Control, 11, 195-200.

Luk, R., \& Ferrence, R. (2005). The economic impact of smoke-free legislation on the hospitality industry (Ontario Tobacco Research Unit, Special Report Series). URL: $\quad$ http://www.hc-sc.gc.ca/hcps/alt_formats/hecs-

sesc/pdf/pubs/tobac-tabac/2005hospitalit/hospitalit-eng.pdf (Accessed on 13/09/2012).

Luk, R., Ferrence, R., \& Gmel, G. (2006). The economic impact of a smoke-free bylaw on restaurant and bar sales in Ottawa, Canada. Addiction, 101, 738-745.

McNabb, J., \& Hearns, N. (2005). The smoking ban in hospitality: a cross-border perspective from Ireland. International Journal of Contemporary Hospitality Management, 17(2/3), 181-190.

Melberg, H. O., \& Lund, K. E. (2009). Did the ban on smoking reduce the revenue in pubs and restaurants in Norway? University of Oslo Working Paper 2009:9. URL: http://www.med.uio.no/helsam/forsknin g/nettverk/hero/publikasjoner/skriftserie /2009/2009_9.pdf (Accessed on 13/09/2012)

Meyer, J. P., Stanley, D. J., Herscovitch, L., \& Topolnytsky, L. (2002). Affective, continuance, and normative commitment to the organization: A meta-analysis of antecedents, correlates, and consequences. Journal of Vocational Behavior, 61(1), 20-52.

Miller, C. L., \& Hickling, J. A. (2006). Phased-in smoke-free workplace laws: reported impact on bar patronage and smoking, particularly among young adults in South Australia. Australian and New Zealand Journal of Public Health, 30(4), 325-327.
Mulcahy, M., Evans, D. S., Hammond, S. K., Repace, J. L., \& Byrne, M. (2005). Second-hand smoke exposure and risk following the Irish smoking ban: an assessment of salivary cotinine concentrations in hotel workers and air nicotine levels in bars. Tobacco Control, 14, 384-388.

National Cancer Institute. (1999). Smoking and tobacco control monographs monograph 10: health effects of exposure to environmental tobacco smoke. URL: http://cancercontrol. cancer.gov/tcrb/monographs/10/m10_c omplete.pdf (Accessed on 13/09/2012).

Nunnally, J. C. (1978). Psychometric theory. $\left(2^{\text {nd }}\right.$ ed.). New York: McGraw-Hill.

Pilkington, P. A., Gray, S., Gilmore, A. B., \& Daykin, N. (2006). Attitudes towards second hand smoke amongst a highly exposed workforce: survey of London casino workers. Journal of Public Health, 28(2), 104-110.

Pizam, A. (2012). Smoking rates among hospitality employees. International Journal of Hospitality Management, 31, 307-308.

Room, R. (2005). Banning smoking in taverns and restaurants - a research opportunity as well as a gain for public health. Addiction, 100, 888-890.

Roseman, M. (2005). Consumer opinion on smoking bans and predicted impact on restaurant frequency. International Journal of Hospitality \& Tourism Administration, 6(4), 49-69.

Scollo, M., \& Lal, A. (2008). Summary of studies assessing the economic impact of smoke-free policies in the hospitality industry. VicHealth Centre for Tobacco Control. URL: http://www.vctc.org.au/tcres/Hospitalitysummary.pdf (Accessed on 13/09/2012).

Siegel, M. (1993). Involuntary smoking in the restaurant workplace: A review of employee exposure and health effects. Journal of the American Medical Association, 270, 490-493.

Skogstad, M., Kjaerheim, K., Fladseth, G., Gjolstad, M., Daae, H. L., Olsen, R., Molander, P., \& Ellingsen, D. G. (2006). Cross shift changes in lung function among bar and restaurant workers 
Pranić, L., Pivac, S. \& Čolak, A. (2013). European Journal of Tourism Research 6(1), 5-19.

before and after implementation of a smoking ban. Occupational and Environmental Medicine, 63(7), 482487.

Tang, H., Cowling, D. W., Stevens, C. M., \& Lloyd, J. C. (2004). Changes of knowledge, attitudes, beliefs, and preference of bar owners and staff in response to a smoke-free bar law. Tobacco Control, 13(1), 87-89.

Tang, H., Cowling, D. W., Lloyd, J. C., Rogers, T., Koumjian, K. L., Stevens, C. M., \& Dileep, G. (2003). Changes of attitudes and patronage behaviours in response to a smoke-free bar law. American Journal of Public Health, 93(4), 611617.

Thomson, G., \& Wilson, N. (2006). One year of smokefree bars and restaurants in New Zealand: Impacts and responses. BMC Public Health, 6, 64-69.

Tutuncu, O., \& Kozak, M. (2007). An investigation of factors affecting job satisfaction. International Journal of Hospitality \& Tourism Administration, 8(1), 1-19.

United Nations Statistics Division. (2011). Composition of macro geographical (continental) regions, geographical subregions, and selected economic and other groupings. URL: http://unstats.un.org/unsd/methods/m4 9/m49regin.htm\#transition (Accessed on 13/09/2012).
Wakefield, M., Roberts, L., \& Miller, C. (1999). Perceptions of the effect of an impending restaurant smoking ban on dining-out experience. Preventive Medicine, 29, 53-56.

Wan, Y. K. P., \& Pilkington, P. A. (2009). Knowledge, attitudes and experiences of Macao's casino workers with regard to second-hand smoke exposure at work. International Gambling Studies, 9(3), 207-224.

World Health Organization. (2011a). Tobacco (Fact sheet $N^{\circ} 339$ ). URL: http://www.who.int/mediacentre/factshe ets/fs339/en/index.html (Accessed on 13/09/2012).

World Health Organization. (2011b). WHO report on the global tobacco epidemic, 2011: country profile Bosnia and Herzegovina.

URL: http://www.who.int/tobacco/surveillance /policy/country_profile/bih.pdf (Accessed on 13/09/2012).

World Health Organization. (2008). WHO report on the global tobacco epidemic: The MPOWER package. Retrieved from http://www.who.int/tobacco/mpower/mp ower_report_full_2008.pdf (Accessed on $1 \overline{3} / 09 / 2012)$. 